\title{
Analysis of the Impact of Aquatic Weeds in the Shire River on Generation of Electricity in Malawi: A Case of Nkula Falls Hydro-Electric Power Station in Mwanza District, Southern Malawi
}

\author{
Maureen Kapute Mzuza1,2*, Lostina Chapola1, Fanuel Kapute ${ }^{3}$, Innocent Chikopa1, \\ Jimmy Gondwe ${ }^{1}$ \\ ${ }^{1}$ Department of Geography, Catholic University of Malawi, Limbe, Malawi \\ ${ }^{2}$ State Key Laboratory of Estuarine and Coastal Research, East China Normal University, Shanghai, China \\ ${ }^{3}$ Department of Fisheries Science, Mzuzu University, Mzuzu, Malawi \\ Email: maureenmzuza@yahoo.com
}

Received 31 May 2015; accepted 23 June 2015; published 26 June 2015

Copyright (C) 2015 by authors and Scientific Research Publishing Inc.

This work is licensed under the Creative Commons Attribution International License (CC BY).

http://creativecommons.org/licenses/by/4.0/

(c) (i) Open Access

\section{Abstract}

A study was carried out to analyse the extent to which diverse species of aquatic weeds that have proliferated in the Shire River in Malawi in recent years affect the generation of electricity at Nkula Hydro-Electric Station in Mwanza District of the southern region of the country. Specifically, the study endeavoured to establish whether frequent power interruptions that Malawi is facing are the result of the problems caused by aquatic weeds in the Shire River which are believed to disturb proper functioning of the machines at the power station. Study results revealed that as much as the aquatic weeds impede power generation such as blocking the turbines, problems of low power generation that result into frequent and persistent load shedding are not entirely due to aquatic weeds. Problems of inefficient machines and shut down of machines are due to serving, which appeared to be the major cause.

\section{Keywords}

Aquatic Weeds, Electricity Generation, Load Shedding

\footnotetext{
${ }^{*}$ Corresponding author.
} 


\section{Introduction}

Electricity is a backbone to the development of a country. Many manufacturing industries use electricity for their production and people rely on electricity for their daily domestic jobs such as cooking. Hospitals too need electricity for their day-to-day activities. The need for electricity can therefore not be undermined. However, Malawi has recently been facing intermittent electricity blackouts and the Electricity Supply Corporation of Malawi (ESCOM), which provides about $98 \%$ of the electricity in the country [1] [2] is facing a great challenge to meet the demand for power. Its major hydro-electricity power (HEP) station at Nkula Falls along the Shire River, together with other HEPs of Tedzani and Kapichira Falls along the same river are not able to generate enough electricity to meet the ever increasing demand. Only 8\% of the population in Malawi has access to electricity [3]. Malawi is in fact, one of the least electrified countries in the SADC region, with an average per capita consumption of $111 \mathrm{kWh}$ per annum, rated among the lowest in the world [4]. [5] reported that Malawi's power outages are the highest in Africa. [1] reported that Malawi's installed generation capacity is approximately 287 megawatts, of which only about 267 megawatts is available against an estimated demand of approximately 325 megawatts. It further reported that with a projected peak demand of 757 megawatts by 2020, electricity generation capacity needs to increase at an average annual growth rate of 10\%. According to [6], in 2005 alone, Nkula Power Station lost 349.19 hours resulting into load shedding and consequently loss of revenue for ESCOM. [7] estimated that the country is losing 215.6 million dollars a year due to the power outages. These power shortage problems reached a climax when one of the consumer rights body in Malawi-the Consumer Association of Malawi (CAMA) challenged ESCOM in court to stop their motto of "power all day everyday" as this did not reflect their output. ESCOM eventually changed its motto to read "towards power all day everyday". While ESCOM admits that its power generation capacity is below consumer demand, it has directed the problem of persistent power outages on the weeds in the Shire River (Figure 1) where Nkula Hydro-electricity power station is built.

Since late 1990s, aquatic weeds which have not caused any environmental concern in the Shire River have found their way into the power generation plant at Nkula Falls HEP [2]. Increase in the aquatic weeds has resulted into an increase in floating aquatic weeds and debris in addition to siltation at the intake ponds (Figure 2).

The Aquatic weeds have caused extensive damage to ESCOM's hydroelectric generation machines. For example, in December 2001, intake structures at Tedzani I \& II Power station were completely devastated due to weeds that had accumulated at the intake screens resulting into the collapse of the intake screens [2]. [8] also reported similar damages by floating debris for Kapichira Power station which necessitated installation of weed barriers. This was also earlier reported by [9] [10]. The major objective of this study was therefore to analyse and document the effects of aquatic weeds at Nkula-Dam on the production of hydro-electricity at Nkula Hydro Electric Power Station.

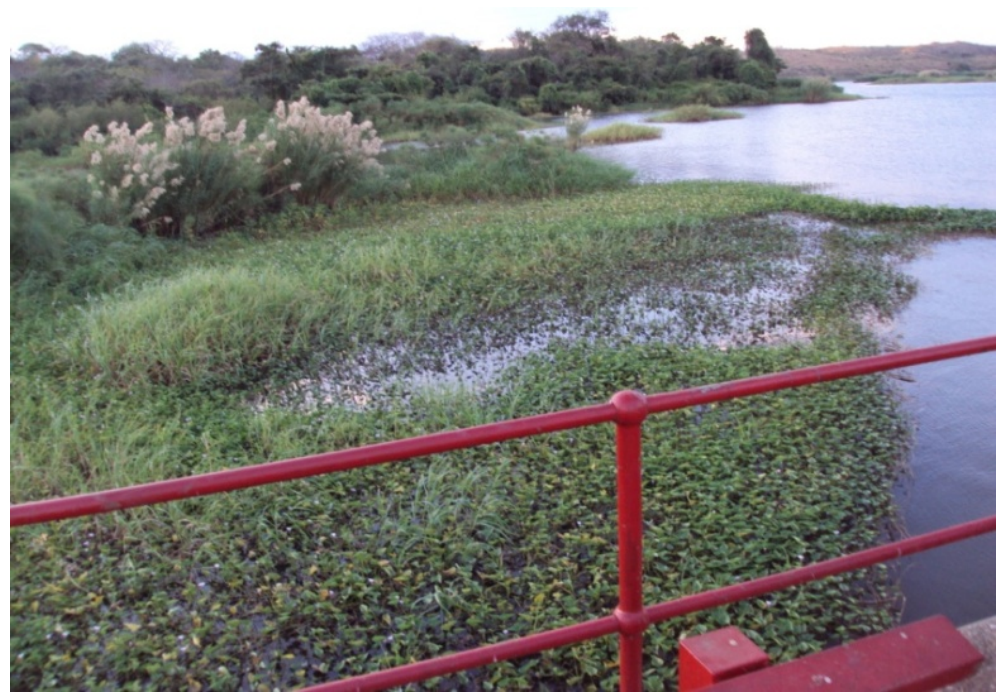

Figure 1. A combination of several grass species-Water hyacinth, reeds, water lettuce and others at the Nkula Falls Intake. 


\section{Materials and Methods}

A three-year electricity generation data between 2007 and 2009 was sourced from the power generation house at Nkula Falls Hydro Electricity Power Station in Mwanza district of southern Malawi. The case study of the problems of aquatic weeds on production of electricity at Nkula HEP station followed a conceptual framework model modified from [6] [8] [11] (Figure 3). Nkula Falls Hydro-Electricity Power Station is the first in a series of HEPs from Liwonde barrage on the Shire River where most aquatic weeds are trapped and collected.

Theoretical model gives the possible reasons that could explain some of the causes of blackouts. For example, the presence of aquatic weeds causes clogging of turbines and intake screens and reduction of water level consequently resulting in frequent blackouts. The machines used are old and commonly breakdown resulting in low production of electricity which also result in blackout.

\section{Statistical Data Analysis}

Data were entered into the computer Microsoft Excel spread sheet then analyzed using Statistical Package for Social Scientists (SPSS version 15.0). Independent Sample t-Tests were computed to compare means for power generation loss caused by trash and other factors.

\section{Results}

Most ESCOM employees interviewed on site indicated that aquatic weeds mainly Water hyacinth (Eichhornia
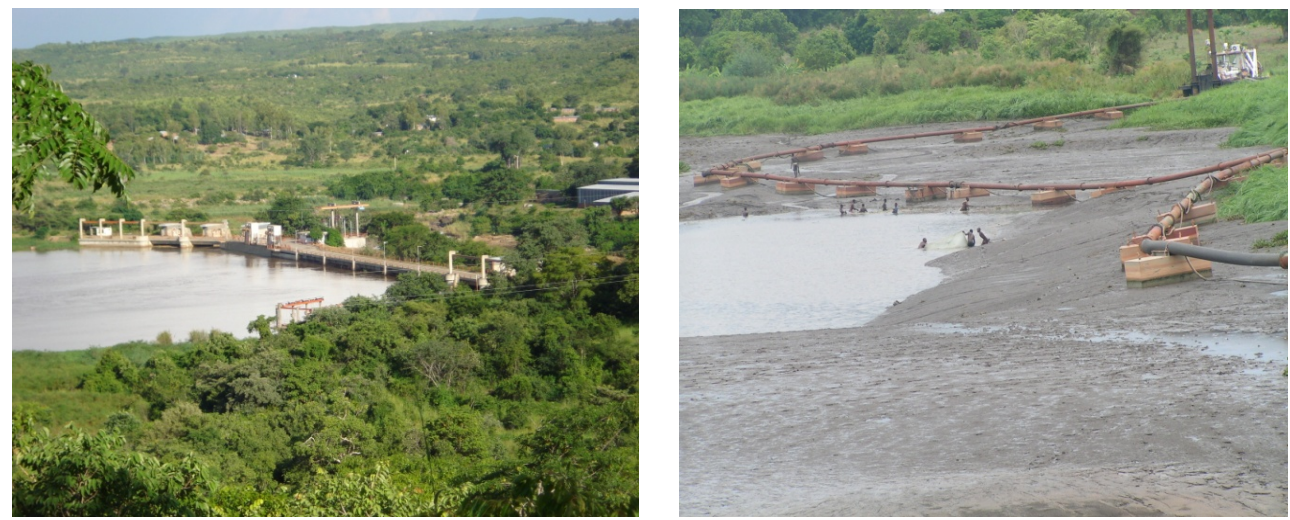

Figure 2. The water intake dam at Nkula Falls on the Shire River (left); heavy siltation (right).

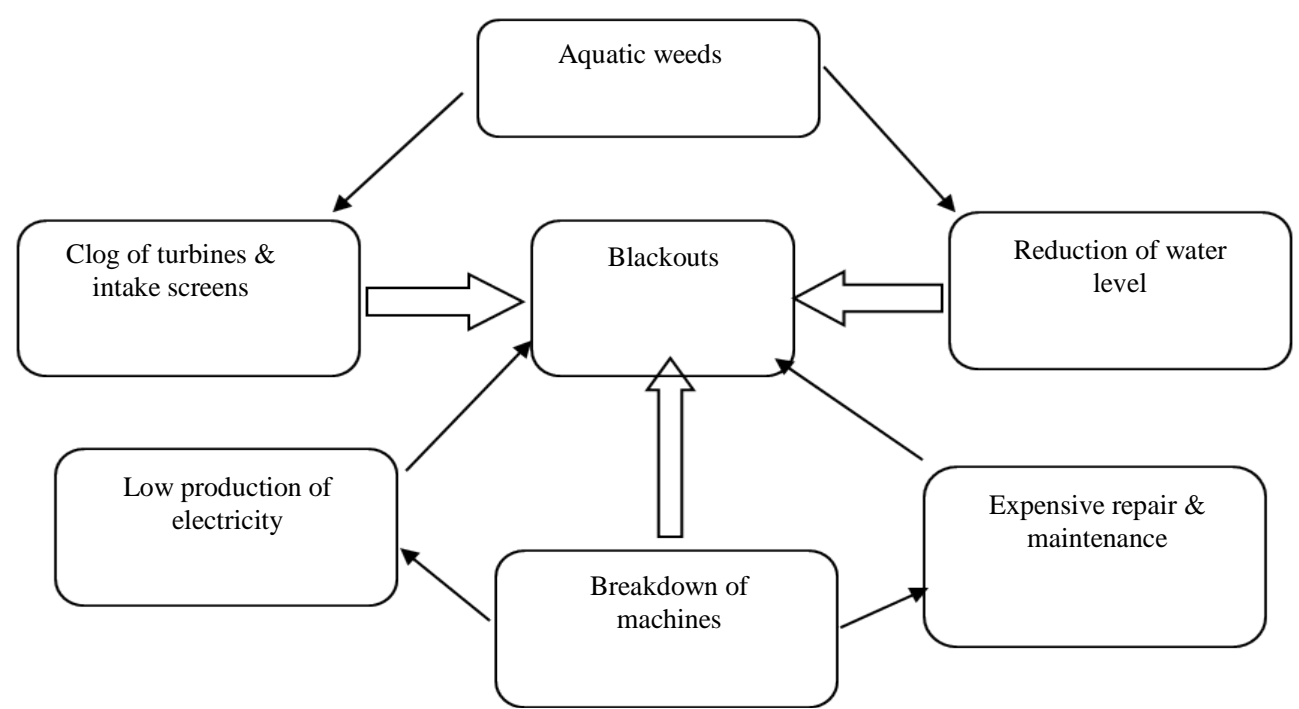

Figure 3. Theoretical model (modified from [6] [8] [11]). 
crassipes), had been seen in the Shire River since the 1990s. One of the longest serving employees who started working with ESCOM in 1979 also reported to have seen Water hyacinth in the Shire River in the 1990s. Results from data on energy loss in megawatts per hour (MWhr) from July 2007 to June 2008 are presented in Figure 4.

Based on results in Figure 4, it was apparent that energy generation losses that were incurred by ESCOM due to removal of trash at the intake were far much lower compared to losses due to other problems that affected power generation. In fact, there were highly significant differences $(\mathrm{P}<0.05)$ (Table 1$)$ confirming the observation that more energy was lost as a result of some factors other than effect of aquatic weeds.

It was further shown that energy production loss due to trash (aquatic weeds) did not even amount to half of the period i.e. 5 months in a year as highest energy losses were due to other reasons/causes other than trash. Some of the reasons expressed by the engineers at the HEP included: low oil level in the turbine bearing basin, turbine bearing basin leaking, trip due to loss of station supplies, repair Gov main oil pump/removing pump, repair Gov main oil pump/replace repaired Gov oil pump and low water level at Nkula-dam due to high level of siltation. For example, in January, 2015 there were a lot of blackouts in many areas because ESCOM was removing silt at Nkula-Dam which was affecting the water level. A summary of these findings indicated that "other reasons" were to a greater extent responsible for power generation problems than those arising from removing trash at the intake. Results obtained from January to June 2009 (Figure 5) for power generation data for Nkula HEP Station similarly suggested that problems of trash were not the major cause for power generation loss at Nkula HEP Station.

Except for the situation in 2009 (Figure 5) where effect of trash was observed in rainy season (January to March), results (Figure 4) also indicated that aquatic weed accumulation at the intake was not only in rainy season. The observation that the effect of trash was also recorded in July and October (Figure 4) i.e. months
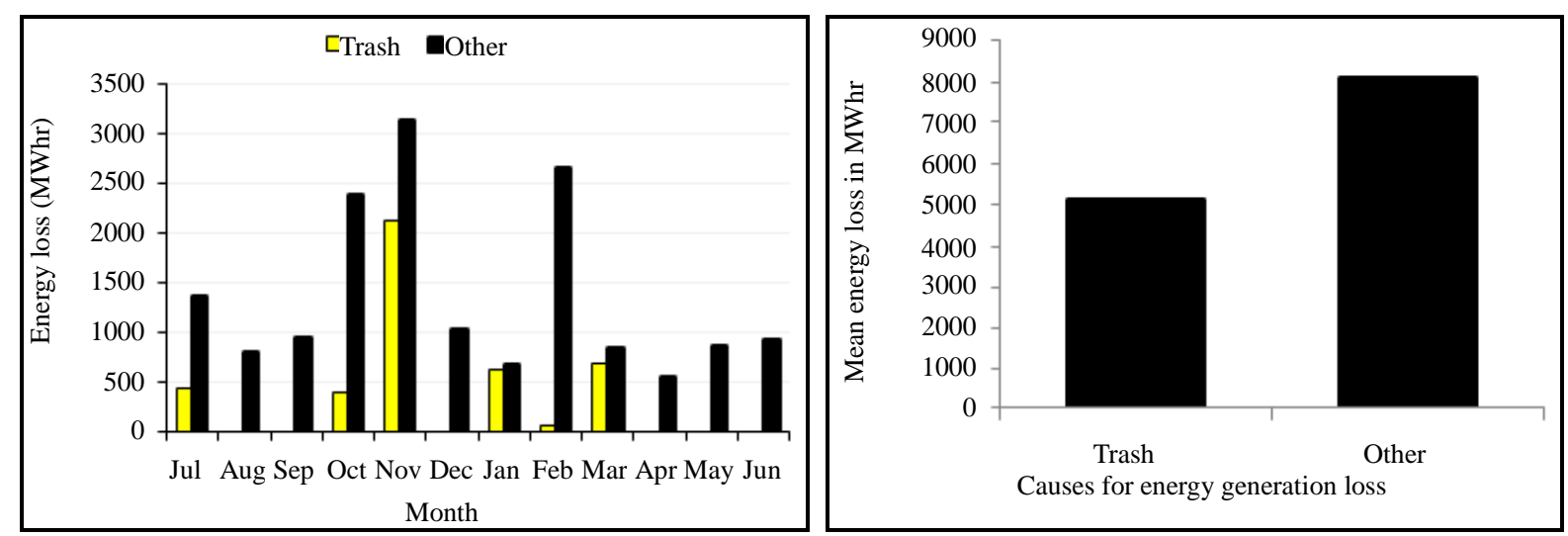

Figure 4. Energy generation losses due to trash and other causes for Nkula Falls A and B Hydro-Electricity Power Station between July 2007 and June 2008 (left) and summary (right).

Table 1. t-Test: Paired two sample for means of energy loss due to trash and other causes.

\begin{tabular}{ccc}
\hline & Trash & Other \\
Mean & 360.3683333 & 1358.89417 \\
Variance & 378208.002 & 754292.643 \\
Pearson Correlation & 0.594219151 & -4.902864532 \\
$\mathrm{t}$ Stat & 0.000234738 \\
$\mathrm{P}(\mathrm{T} \leq \mathrm{t})$ one-tail & 1.795884819 \\
$\mathrm{t}$ Critical one-tail & 0.000469476 \\
$\mathrm{P}(\mathrm{T} \leq \mathrm{t})$ two-tail & 2.20098516 \\
$\mathrm{t}$ Critical two-tail & \\
\hline
\end{tabular}


when nearly all parts in Malawi do not receive rains_-dry season, suggested that problems of aquatic weeds occur not only during rainy season as is reported by ESCOM. Probably this could be directly related to how much rain was received from the river's catchment area. The high power production losses in November (Figure 4) due to both trash and other reasons could be attributed to the fact the southern region of Malawi receives rains much earlier than the central and northern regions of the country. The other causes to loss in power generation included repairing of machines such as greasing, runner repairs, brush gear sparking and general breakdown of the machines. Other minor reasons included power disruption by vandalism of ESCOM transformers and animals being short-circuited on power lines (Figure 6).

Differences in daily machine performance were also observed as power production varied from 179,000 to 159,000 MW while running for 24 hours. For example, in June 2009 (Figure 7), power production fluctuated even during days when machines were running for 24 hours in a day. Thus, even with an exception of the 2 days when there was no power production during repairing of leaking in the turbine basin, power production fluctuation continued.

It can be suggested therefore that even without the effect of the aquatic weeds, significant losses in electricity generation of HEP machines would still be observed. This means therefore that there should be other notable reasons like low water level at Nkula-dam due to siltation that resulted in reduction of electricity generation other than effect of aquatic weeds (trash) which is always believed to be the major cause.

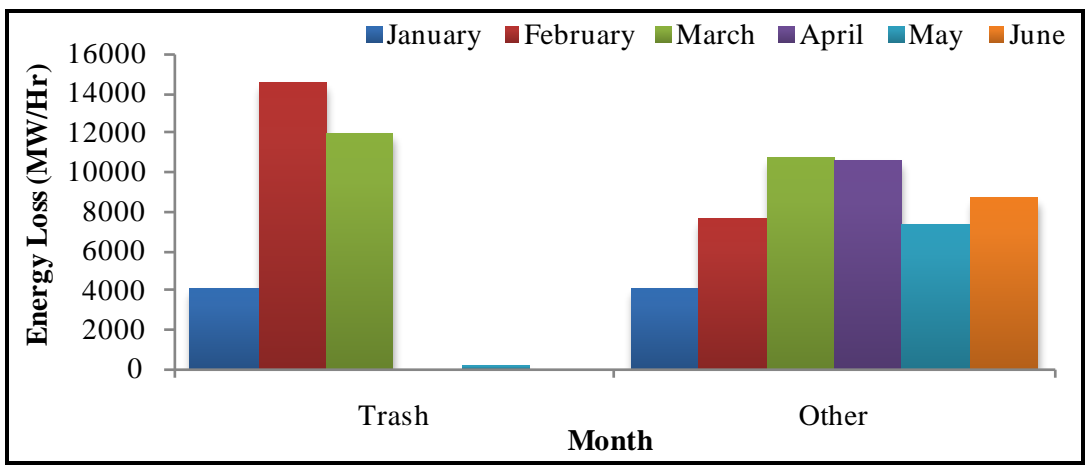

Figure 5. Energy loss (MWhr) of energy loss due to trash and other causes for Nkula HEP from January to June 2009.

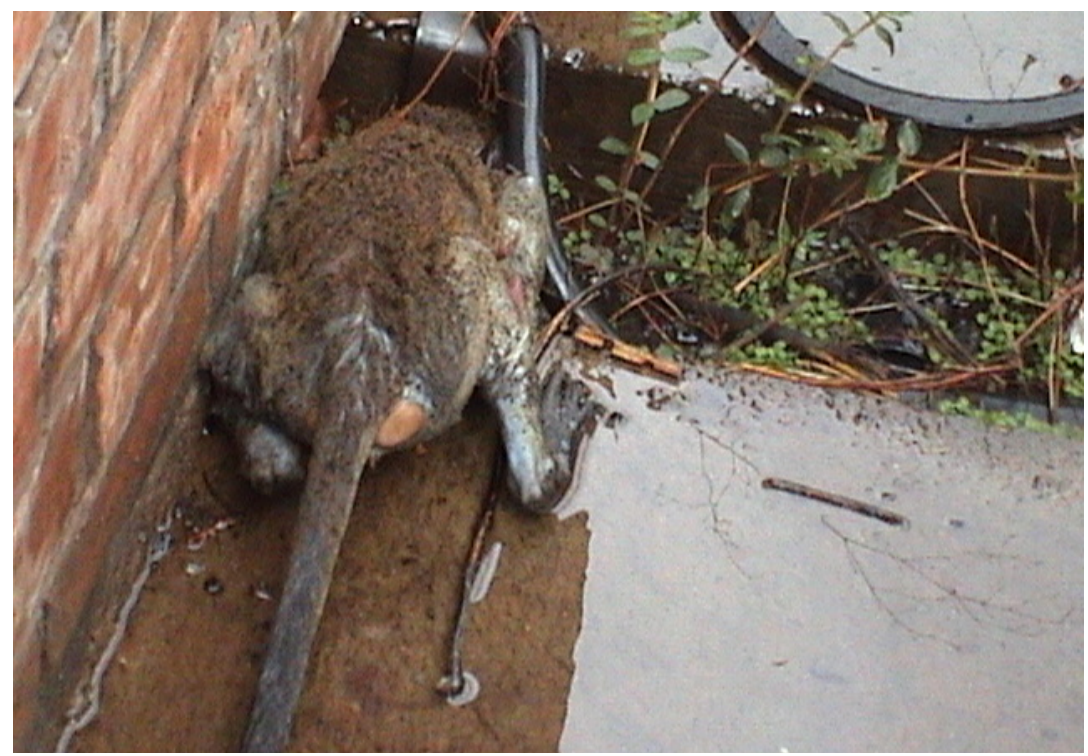

Figure 6. A monkey that landed on an ESCOM transformer resulting into power cut (Photo kindly provided by Nkula HEP Station personnel). 


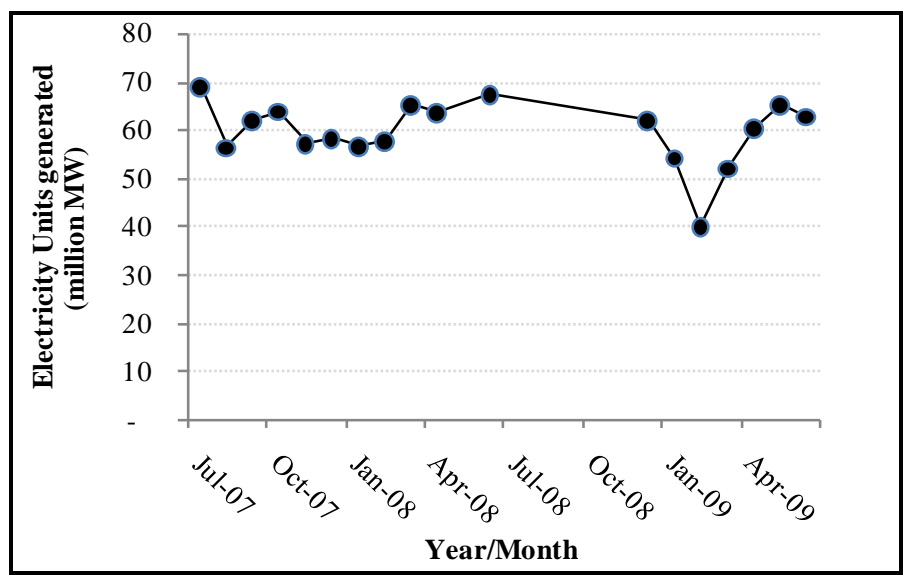

Figure 7. Amount of units (MWHr) generated per day between July 2007 and May 2009 at Nkula HEP.

\section{Discussion}

It could be most likely that [12] who reported that floating aquatic weeds started becoming a problem in the Shire River and finding their way into the intake dam at Nkula Falls from the 1990s sought information from the same source. It is reported that aquatic weeds started infesting massively African freshwater bodies during the early 1950s and rapidly spread in many countries [13]. In fact, ESCOM power stations operated without any major environmental problems until 1990s when there was an increase of floating aquatic weeds and debris in addition to silt deposition at the intake ponds [2] [3]. In recent years, there has been a dramatic increase in the onset of floating aquatic weeds on the river so much so that electricity generation has been greatly affected especially during the rainy seasons [2].

The impact of aquatic weeds on generation of hydro-electricity has been documented by several reporters [3] [12]-[14]. Damaging effects include pumps and turbines in super thermal power stations and hydroelectric power stations influencing electric production which consequently increases the cost of maintenance of power stations [14]. For example, in December 2001, the intake structures at Tedzani Falls I \& II were blocked by accumulated weeds and repairing the screens and returning the station to service cost more than US\$12 million [2]. In 2009, weed infestation caused damage to the intake screens of the biggest power station resulting into loss of $124 \mathrm{MW}$ [4]. It is also reported that though staff in ESCOM's generation business unit have long experience of operating hydropower plants, problems in financing have hampered reduction in the risks to turbines and generators caused by trash and sediment [15].

However, despite the reported significant impact that is brought about by aquatic weeds in the Shire River, results in this study (Figure 4 and Table 1) showed that generation of power was not entirely or directly due to the effect of aquatic weeds but rather other reasons. For example, losses in electricity generation due to the removal of weeds at the intake dam did not even amount to half of the period between July 2007 and June 2008. Engineers spent more time fixing problems such as low oil level in the turbine bearing basin, turbine bearing basin leaking, trip due to loss of station supplies, repairing and replacing Gov main oil pump/removing pump etc. [16] reported that frequent equipment breakdown has contributed to losses in power generation in Malawi. [3] quoted a senior ESCOM employee saying "during the Easter Holiday, ESCOM repairs equipment from the head-ponds. We lose revenue once we halt operations but such repair works on Easter Holidays are crucial to us as ESCOM. Just this year, we first closed Tedzani Power Station on Friday and Sunday and then Nkula Power Station later to ensure that most parts still have power." It is sufficing to note that by 2007, ESCOM reported that the aquatic weed problem had been put under control through a program of vegetation cutting and harvesting, combined with a system to trap floating weeds [2] [5] suggesting that the maintenance of equipment may not have been as a result of damage by aquatic weeds.

Results for this study agreed with [2] that aquatic weeds were most prevalent in the river Shire during the rainy season (January to March or April) (Figure 5). Also, the report by [2] that rising water levels dislodges roots of weeds that had grown on the river banks during the dry season, causing them to float into the water was clearly observed in this study where power generation loss was recorded even in dry months of October and July. 
[2] reported further that during the 2007 rainy season, there were virtually no plant shutdowns due to trash by comparison with 2005 where the Nkula Falls Power Station facility lost 349.19 hours to shutdowns [2] [5]. This indicates that problems of aquatic weeds occur throughout the year and not in the rainy season only as ESCOM puts it. A report by [4] indicated that load shedding has become rampant following the loss of $40 \mathrm{MW}$ generation capacity in 2001 when one of the power stations was flooded. In 2003, another 100 MW was lost as a result of flooding. The power station was restored within 4 months, however the efficiency of the plant has been negatively affected, and the life span of some major components has been reduced drastically. [4] reported further that underinvestment in ESCOM has resulted in acute shortages of generation capacities and deterioration in the quality supply of such that the system is operating on negative generation reserve capacity. It has been reported by [15] that ESCOM has had inadequate financial resources to ensure proper maintenance of generation and transmission assets resulting into problems of poor generation availability and reliability. These have also led to low levels of investment in transmission and distribution, leading to overloaded equipment, low supply reliability and poor quality supply.

ESCOM equipment is costly hence any type of damage is significant. That is why scenarios of animals such as monkeys falling and being electrocuted over electric wires cannot be under estimated (Figure 6). Vandalism of ESCOM equipment also continues to be on the rise resulting into the company spending a lot of money maintaining its equipment [17].

The study also observed differences in daily machine performance as power production varied from 179,000 to 159,000 MW while running for 24 hours. For example, in June 2009, power production fluctuated even during days when machines were running for 24 hours in a day (Figure 7). This might be due to low water level at Nkula-Dam which is a result of high level of siltation at the dam.

\section{Conclusion}

It was apparent from the findings that none of the problems causing electricity generation losses at Nkula Falls HEP were related or caused by aquatic weeds. Rather, results showed that other reasons play a key role chiefly siltation, inefficiency of the machines/equipment and frequent repairs. Problems of load shedding are generally due to the fact that electricity generated by ESCOM is by far below from meeting the demand especially due to increase in population. Low level of water due to high siltation in the Nkula-Dam might be a big contributing factor. Therefore there is need for more research to investigate the sources and effects of siltation in the dam.

\section{Acknowledgements}

Authors sincerely thank the staff of ESCOM at Blantyre Head office, Nkula Falls Hydro-Electricity Power Station and Liwonde Barrage for kindly providing the electricity generation data and freely giving more information regarding its operations.

\section{References}

[1] Millennium Challenge Corporation (2010) Malawi Power System Project Studies. Final Feasibility Study Report. ICF International/Core International, Inc., Washington DC.

[2] Liabunya, W.W. (2007) Malawi Aquatic Weeds Management at Hydropower Plants. In: Proceedings of Hydro Sri Lanka, the International Conference on Small Hydropower, Kandy, 22-24 October 2007, 1-9.

[3] Mhango, G. (2012) Malawi: Aquatic Weeds and Silt Lead to Power Deficiency. WaterSan Perspective. http://waterjournalistsafrica.wordpress.com/2012/05/18/malawi-aquatic-weeds-and-silt-lead-to-power-deficiency/

[4] The Government of the Republic of Malawi (2009) Millennium Challenge Account, Compact Program for (20112016). Concept Paper for the Energy Sector. Malawi Country Office Secretariat. The Government of the United States of America Millennium Challenge Corporation, Lilongwe.

[5] World Bank (2009) Power Tariff Reform, Malawi in an International Context. Blantyre. www.hydroworld.com

[6] Liabunya, W.W. (2006) Liwonde Aquatic Weeds Management Project. (A paper presented at the 18th Africa Hydro Symposium on 13th October).

[7] Millennium Challenge Account Malawi (2012) Environment Component of the Malawi Compact. Lilongwe. https://www.mcc.gov/pages/countries/program/malawi-compact

[8] Kandoje, A. (2005) Proposal on Trash Management Structures for Kapichira Power Station, April, 2005. 
[9] Makhan, K. (1997) 23rd Conference on WEDC Conference on Water Quality and Treatment. http://www.wedc.iboro.ac.uk

[10] Gopal, B. (1987) Water Hyacinth. Elsevier Science Publishers, Amsterdam, 477p.

[11] Chapalapata, D. (2005) Problems of Aquatic Weeds and Power Generation in ESCOM. A paper presented at the 17th Africa Hydro Symposium.

[12] Chapalapata, D. (2009) Aquatic Weeds Harvesting. Weeds Control ESCOM Limited Report.

[13] Mitchell, D., Pieterse, A. and Murphy, K. (1990) Aquatic Weed Problems and Management in Africa. In: Pieterse, A.H. and Murphy, K.J., Eds., Aquatic Weed, the Ecology and Management of Nuisance Aquatic Vegetation, Oxford University Press, Oxford, 341-354.

[14] Lancar, L. and Krake, K. (2002) Aquatic Weeds \& Their Management. International Commission on Irrigation and Drainage (ICID.CIID).

[15] Millennium Challenge Account (2009) Malawi Government, Concept paper for the energy sector public private partnerships on electricity generation for rural areas. Malawi Country Office Secretariat, Lilongwe, Malawi (2011-2016).

[16] World Bank (2012) Project Appraisal Document on a proposed Credit and Grant and a Proposed Grant from the Global Environment Facility Trust Fund/Least Developed Countries Fund. Republic of Malawi for a Shire River Basin Management Project in Support of the first phase of the Shire River Basin Management Program Lilongwe, Malawi.

[17] Millennium Challenge Account-Malawi Country Office Secretariat (2011-2016) The Government of the United States of America Millennium Challenge Corporation Compact Program for the Government of the Republic of Malawi (2011-2016). Concept Paper for the Energy Sector, Lilongwe, Malawi. http://www.google.com/url?sa=t\&rct=j\&q=\&esrc=s\&source=web\&cd=5\&ved=0CDoQFjAE\&url=http\%3A\%2F\%2F www.mca-m.gov.mw\%2Findex.php\%2Fresource-centre\%2Fdocuments\%2Fcategory\%2F6-concept-papers\%3Fdownlo ad\%3D15\%3Amca-energy-concept-paper-29042009\&ei=OoyJVdTDNfCf7gaFraTgBA\&usg=AFQjCNHTXretUlQvX J68awpMvvWXPBwTgQ\&sig2=V7AwE49hSu1a1ai6J1Lk_w\&bvm=bv.96339352,d.ZGU 